\title{
THE INTELLIGENCE OF CHILDREN WITH CLEFT PALATE
}

\author{
BY \\ R. S. ILLINGWORTH and L. B. BIRCH \\ From the Department of Child Health and the Institute of Education, the University of Sheffield
}

(RECEIVED FOR PUBLICATION MARCH 28, 1956)

When a baby is born with a serious congenital anomaly, such as hare lip and cleft palate, the paediatrician should be in a position from factual knowledge to discuss with the parents the prognosis of that condition, including the outlook for mental development. One of us (R.S.I.) recently witnessed a father's rejection of a newborn baby with marked hare lip. He said that he could not possibly allow the child to be taken home, and that it would have to be adopted. Discussion gave him a better understanding of the problem and led to his changing his mind. In such a case the paediatrician must have a knowledge of the prognosis, with particular regard to facial appearance and mental development.

We have been unable, in a thorough search of the literature, to find factual evidence concerning the intelligence of children with cleft palate. The impression of one of us (R.S.I.) was that a high proportion of these children proved to be mentally defective. The only reference to the subject which we have been able to find was in the book Inheritance of Harelip and Cleft Palate by Fogh-Andersen (1943) based on a study of 703 cases. He stated:

'It is as likely as not that the frequency of associated defects of intellect exceeds the accident coincidence.'

Among 17,000 feeble-minded individuals examined by the University Institute of Human Genetics at Copenhagen, there were 59 cases of hare lip and cleft palate. The expected incidence would be 20 , so that the frequency far exceeded the expected figure. Fogh-Andersen stated that he had no other facts about the problem.

\section{The Present Study}

One hundred and twelve names in alphabetical order were taken from the list of the plastic surgeon, Mr. W. Hynes. The only patients excluded were those who were under 4 years of age. Sixty were boys and 52 were girls. The ages varied from 4 to
16 years, with a mean age at the time of testing of $7 \frac{3}{4}$ years. Fifty-four of these had a hare lip and cleft palate; 58 had a cleft palate alone. The patients came from a wide area, mostly from Yorkshire, Lincolnshire, Nottinghamshire and Derbyshire, and a few came from further afield. They were in no way selected in regard to social class, for very few cleft palate patients were treated privately, and the few who were, estimated at two in the last four years, were treated by the same surgeon. (One such case was included in the study. His I.Q. was 90.)

Having obtained the names, we wrote to the parents, explaining the purpose of the study, and offering to pay travelling expenses if they amounted to a shilling or more. The result was disappointing, largely on account of distance. In all 61 came for testing. Two had died. We then asked for the help of the appropriate medical officers of health and school medical officers, and they had a further 19 tested and sent school reports on a further 17. A total of 80 , therefore, had a full intelligence test. We were unable to obtain any information about the remaining 13 (Table 1).

TABLE 1

CHILDREN WITH CLEFT PALATE WITH AND WITHOUT HARE LIP

\begin{tabular}{|c|c|c|c|c|c|}
\hline Number of & Cases Tested & \multirow{2}{*}{$\begin{array}{l}\text { No. of Cases } \\
\text { with School } \\
\text { Reports }\end{array}$} & \multirow[b]{2}{*}{ Died } & \multirow[b]{2}{*}{$\stackrel{\text { No }}{\text { Record }}$} & \multirow[b]{2}{*}{ Total } \\
\hline $\begin{array}{c}\text { At Institute } \\
\text { of Education }\end{array}$ & $\begin{array}{l}\text { By Local } \\
\text { Authorities }\end{array}$ & & & & \\
\hline 61 & \multirow[b]{2}{*}{$1 \%$} & \multirow[t]{2}{*}{17} & 2 & 13 & \multirow[t]{2}{*}{112} \\
\hline $80(71 \%)$ & & & \multicolumn{2}{|c|}{$15(13 \%)$} & \\
\hline
\end{tabular}

The test used by the Institute of Education and by the local authorities was the Terman and Merrill test.

\section{Results}

The results reveal a range of scores comparable with that of the general population, the highest being 
140 , and the lowest below 50 . There were, however, more scores below the average than above it, the mean I.Q. being $95 \cdot 4$, with a standard deviation of $19 \cdot 5$. This mean is significantly lower at the $5 \%$ level than an assumed population mean of 100 . Kennedy-Fraser (1949) in a study of a truly representative sample of 1,215 11-year-old Scottish children found a mean I.Q. on the same test of $102 \cdot 5(\sigma 20.05)$. There are no available studies of English children for comparison with our series.

The distribution of scores is shown in Table 2. Two of the cases scoring I.Q.s of less than 50 were arbitrarily given a ratio of 45 , though one at least of those was very considerably below this level. One had an I.Q. of 50. Forty-seven had an I.Q. of less than 100, and 33 an I.Q. of over 100.

TABLE 2

RANGE OF INTELLIGENCE QUOTIENTS OF 80 CHILDREN WITH CLEFT PALATE

\begin{tabular}{|c|c|}
\hline I.Q. Range & Frequency \\
\hline $\begin{array}{c}131-140 \\
121-130 \\
111-120 \\
101-110 \\
91-100 \\
81-90 \\
71-80 \\
61-70 \\
51-60 \\
41-50\end{array}$ & $\begin{array}{r}2 \\
2 \\
12 \\
17 \\
15 \\
15 \\
9 \\
3 \\
2 \\
3\end{array}$ \\
\hline Total & 80 \\
\hline
\end{tabular}

\section{Interpretation}

The anomaly of cleft palate alone is genetically distinct from that of cleft palate and hare lip, and we therefore analysed the results for the two groups separately. There was no significant difference in the intelligence of these groups.

In order to determine roughly whether any unknown bias had occurred in the patients who had the Terman and Merrill test, we have studied the information available on the remaining 17 cases.

In the reports of five of the 17 cases the children are referred to as being above average in ability. One is a grammar school boy who will be taking his General Certificate of Education this year ; another is at a technical school having obtained an I.Q. of 106 on a Moray House test. Three others are in ' $A$ ' streams in junior schools.

A further five cases are said to be of average ability and there are intelligence test results in two of them. One scored 103 on the Valentine individual test and another had a mean score of 94 upon two Moray House tests.

There are seven cases in the 17 who are reported as very much below average ability. Of these one has actually been ascertained as being educationally subnormal though unfortunately no actual test results are available. Three are in special classes for backward children and the others are variously reported as being very backward though not sufficiently so to warrant transfer to a special school for educationally subnormal children. One of these children had a mean I.Q. of 86 in two Moray House tests.

Even when the fact that these reports by teachers are based largely upon the attainments of the children and not upon intelligence test results it would seem that had they all been tested their mean I.Q. would not have been higher than the figure of 95.4 found for the tested group and in fact it might easily have been rather lower.

Of the 13 cases about whom no estimate of ability could be obtained, the letters to three inviting cooperation were returned by the post office because they could not be traced, in one case the child had left school, one was too ill to come, one was not asked through a clerical oversight and one parent could not come because of the distance. It is not known whether the remaining six letters reached their addresses, though it is known that in two of these cases the children were being educated in private schools.

In this small group there seems nothing to indicate that any biased selection has taken place which would have resulted in the I.Q.s of the group actually tested being lower than those of the remainder. In further support of this contention it is usually found, as we have done in another enquiry of a similar kind in the same area, that selection works the other way. Cooperation is usually most likely among parents of higher ability who tend to have children of above average intelligence.

It is considered, therefore, that there is a tendency for hare lip and cleft palate to be associated with less than average intelligence. This does not, of course, prove that the two disabilities are genetically connected with intelligence in the usual sense. The disfigurement of hare lip and the speech handicap of hare lip and cleft palate will in the past have been a severe handicap in marriage and it seems likely that sufferers will have had to accept mates of inferior social status and appearance, both of which are known to be in small degree associated with less than average intelligence. Hence in each generation where the disability has revealed itself there will have been a tendency for this differential mating and a lowering of the average I.Q. of the offspring.

It will be interesting to repeat this survey in, say, 15 years to see whether the lessening of the handicap by modern surgical techniques will have caused the mean I.Q. of cleft palate and hare lip patients to 
have moved nearer to the mean of the general population.

\section{Summary and Coachesions}

Information was sought on the intelligence quotient of children with cleft palate with or without hare lip.

Of the 112 children taken without bias from an alphabetical list, two had died, 80 had a Terman and Merrill test, school reports were obtained on a further 17 children, and we have no records concerning 13.

The average I.Q. of those tested was less than the average figure for the population as a whole, averaging $95 \cdot 4$. Forty-seven had an I.Q. of less than $100 ; 33$ had an I.Q. of over 100 . The school reports of the additional 17 children gave the impression that the intelligence of those children was very similar to that of the tested ones.
We wish to thank the Board of Governors, the United Sheffield Hospitals, for defraying travelling costs of parents who brought their children for intelligence testing.

We also wish to thank Mr. W. Hynes, plastic surgeon, the United Sheffield Hospitals, for giving us access to his cases and records; to Miss Crowley, the Lady Almoner of the Children's Hospital, for helping to trace some of the patients; to Sister K. Booth, of the Children's Hospital, for supplying the names and notes; and to the following medical officers and others who so kindly cooperated in obtaining and supplying information about the children who failed to come up for the special examination and testing: Drs. W. T. G. Boul, W. S. H. Campbell, C. D. Cormac, D. J. Cusiter, B. R. A. Demaine, G. Higgins, C. W. W. Jeremiah, Mr. J. L. Longland, Drs. E. K. Macdonald, J. Maclachlan, L. F. McWilliams, J. E. Masterson, J. B. S. Morgan, G. A. W. Neill, G. Randall, R. G. Sprenger, J. A. Stirling, M. C. Taylor and J. M. Watt.

Refenences

Fogh-Andersen, P. (1943). Inheritance of Harelip and Cleft Palate.

Kennedy-Fraser, D. (1949). The Trend of Scottish Intelligence. Scottish Council for Research in Education. London. 